\title{
The Impact of Language Skills Guidance on Children With Hearing Impairment Language Development
}

\author{
Endang Purbaningrum, Khofidotur Rofiah \\ Universitas Negeri Surabaya \\ Surabaya, Indonesia \\ khofidoturrofiah@unesa.ac.id
}

\begin{abstract}
Hearing impairment in children may inhibit their language skill, which in turn disturbs their social interaction. Even though other potentialities in those children may be promising, such impairment may give difficulties in their improvement, a condition that is not in line with the objective of psychiatry. This research was aimed to identify the influence of speech training with a communicative approach to language skill, I.e., in on word identification, speech reading and pronunciation, in pre-school deaf children. This research used a quasiexperimental pretest-posttest control group design. Results showed that the paired t-test indicated the significant influence of speech training in both groups, whereas, the t-test showed that speech training given to experimental group had significant influence compared to that given to control group.
\end{abstract}

Keywords - language; word identification; speech reading; word pronunciation; deaf children

\section{INTRODUCTION}

Optimizing individual potentials is a mental health goal, considering that it involves many aspects, the disruption to one aspect of potential can lead to ineffectiveness of development on other aspects. Even though the other aspect is actually in good condition, as experienced by deaf children. The impaired hearing function will result in inhibition of language development that can disrupt communications poses so that in a relationship with the environment can not run properly. This can interfere with the development of emotions that will affect the development of his soul which can be a disturbance in the formation: anticipation, empathy, and sympathy in the child's hearing[1].

One is not sick, (2) does not get sick from a stressor, (3) in accordance with its capacity and (4) grows and develops positively[2]. In accordance with these mental health restrictions, the deaf children have a higher risk of experiencing developmental mental disorders, than children who are normal hearing.

Given the prevalence of deaf children is not small as estimated by the Ministry of Social, the number of deaf children is $0.775 \%$ of the total population of Indonesia. While the number of children with hearing impaired school age, 76,745 people. And that can be accommodated in schools for children with hearing impaired a total of 3935 children in the year.

There are still many deaf children who have not had formal schooling opportunities due to the limited extraordinary school tamping for deaf children, and the low number of deaf children who are able to integrate into regular schools. This condition is one of the factors causing the low chance of deaf children to get a better education.

Language development in deaf children is dependent on the intercorrelation of various factors including early intervention, language intervention, and life experiences of children associated with loss of hearing [3]. Therefore, for a deaf child to achieve achievement that approximates the normal academic achievement of children, early intervention and language intervention in deaf children becomes imperative.

Deafness is a condition of individuals whose hearing is deformed and when expressing thoughts or opinions with speech or other sounds adjusts to their frequency and intensity [4], [5]

\section{A. Hearing Impairment}

"Hearing impairment" is used in this study as a broad term covering all degrees and types of hearing loss. A hearing impairment is a hearing loss that prevents a person from completely receiving sounds through the ear[4], [5]. Hearing loss is often classified by means of different categories: mild $(20-44 \mathrm{~dB})$, moderate $(45-69 \mathrm{~dB})$, severe $(70-90 \mathrm{~dB})$ and profound (90dB above) hearing loss. A loss in the profound range is often referred to as deafness. Individuals with hearing impairment may be described as deaf or hard of hearing. 1. "Deaf is defined as a hearing disorder that limits an individual's aural/oral communication performance to the extent that the primary sensory input for communication may be other than the auditory channel"[6]. 2. "Hard of hearing is defined as a hearing disorder, whether fluctuating or permanent, which adversely affects an individual's ability to communicate. The hard-of-hearing individual relies on the auditory channel as the primary sensory input for communication"[1]. 
The hearing function is a very fundamental vehicle for the process of understanding language since human beings are born. In the next stage, the ability to hear is the foundation for both formal and non-formal education.

\section{B. Language Development}

Language development in deaf children further requires special guidance. According to Ling, Northcot and Pollack that with early intervention in language skills the development of the language of children with hearing impairment is very close to language development in normal children [7]

In terms of language deaf children generally have the following characteristics: (1) Poor in vocabulary, (2) difficulty in comprehending long and related sentences, (3) difficulty in understanding phrases containing figurative meanings or words, abstract words and (4) difficult to master the rhythm and style of language.

The limitations of deaf children in hearing and obstructing the development of the child's language lead to limited information received, this can hamper the abstraction so that it can inhibit in reaching a wider knowledge.

According to [8] the average intelligence of a child with hearing impairment is lower than that of a normal hearing child. This can be seen from the results of mental tests in children with hearing impairment, the results are lower than the normal child hearing. But on non-verbal tests, deaf children get close to normal children.

The results of a study by Mac Kane, Feterson found out that the intelligence of hearing-impaired children was lower than that of normal hearing children[9]. While the results of research conducted by Bishop, Kirk and Streng, Buchard and Myklebust get the result that intelligence in children with hearing impairment is not different from normal child hearing.

According to Pinter, a psychologist working at the institution of deaf children suggests that children are deaf in motor and mechanical terms and in concrete intelligence the same as children hear, but in terms of verbal intelligence and in terms of academic ability indicates a limitation compared with children who hear[5].

Guidance on language skills in children with a hearing impairment needs to be given on the basis that the problems they face are very complex. Therefore in order to develop the ability of children with hearing impairment can develop optimally in accordance with the ability and disability, the first step should be given in education is the guidance of language skills[7]. Early intervention in the guidance of language skills will help children with hearing impairment in their development, so it does not differ greatly from normal hearing.

In the guidance of language skills in children with hearing impairment includes (1) listening skills, (2) speaking skills, (3) reading skills, and (4) writing skills. In giving guidance language skills, in essence, using the communicative approach. According to [10] the approach is called communicative language approach.

\section{METHOD}

This research uses a quasi-experimental research design. Type pretest-posttest control group design[11]. The design of this study aims to determine the effect of a manipulated variable by directly controlling the variables that are not relevant. In accordance with the research design used there are four elements that are met for this research program, namely (1) intervention, (2) randomization, (3) the existence of control groups to control the variables outside the intervention, and (4) done pretest and posttest to know the effect of an intervention [11]. The study design is illustrated as follows:

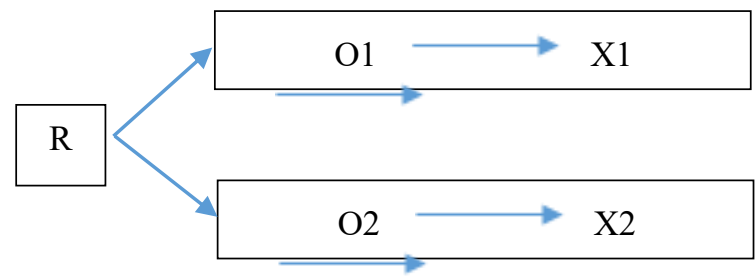

Figure 1. Research Design

Information:

$\mathrm{O} 1=\mathrm{O} 2$ : Samples taken randomly from the population, $\mathrm{O} 1$ is the treatment group and $\mathrm{O} 2$ is the control group

$\mathrm{X} 1$ : Intervention of language skills with a communicative approach that uses props individually.

$\mathrm{X} 2$ : Intervention of language skills with a communicative approach that uses props in a classical way.

O3 : Treatment group sample that has been intervened

O4 : Samples of control groups that have been intervened

\section{A. Population and sample}

The population in this study were children with hearing impairment class at SLB Karya Mulia Surabaya with the following characteristics: (1) children age 4-6 years, (2) normal intelligence level 86-109, (3) $70 \mathrm{~dB}$ (4) has not been interviewed before entering school, (5) has no attention disorder and hyperactivity. Based on these characteristics 25 children of the deaf will be determined as population. Of the population were taken random samples of 20 children.

\section{B. Variable research}

1. Independent Variable: guidance of language skills

2. Dependent Variable: language development in terms of word identification, speech reading, and word pronunciation

3. Control Variable: age, intelligence level, deafness rate, pre-school intervention, attention distraction, and hyperactivity.

\section{RESULT AND DISCUSSION}

Measurement of word identification is done twice before and after the intervention. 


\section{A. Before the intervention}

The average value of word identification ability of 20 respondents is 1.45 with the highest score is 4 and the lowest value is 0 .

Furthermore, the respondents are divided into two groups, namely the treatment groups that follow the guidance of communicative language skills by using props individually and control groups who follow the guidance of communicative language skills by using the props in a classical manner.

The treatment group consisted of 10 respondents, had an average word identification ability of 1.70 . The control group consisted of 10 respondents, having an average score of 1.20

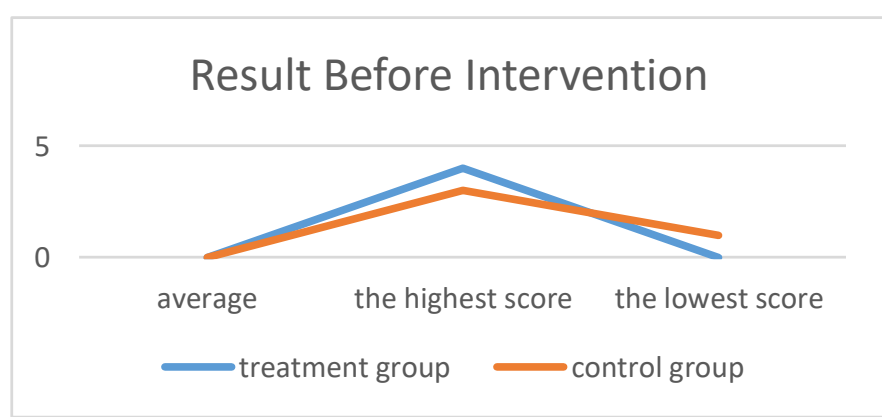

Figure 2. Results of measurement of word identification skills prior to intervention in hearing impaired children

\section{B. Measurement results after intervention}

The average value of word identification ability of 20 respondents was 20.3 and the highest score was 31 , the lowest score was 14. The treatment group had an average value of 23.80 and the control group had an average value of 16.80 .

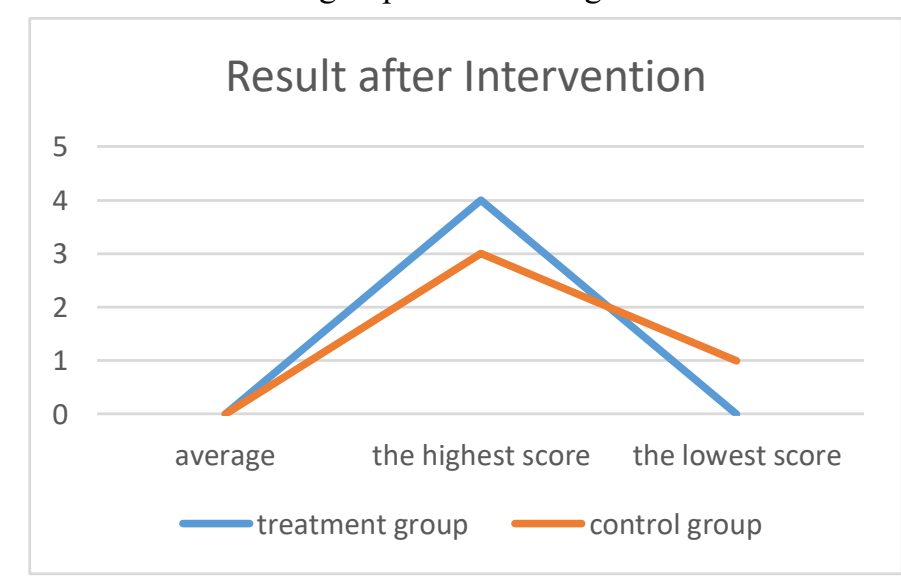

Figure 3. Results of measurement of reading of speech prior to intervention in hearing impaired children

\section{Discussion}

The result of the influence of language skill guidance between treatment group and control group

Before the intervention of treatment group and control group in language skills in terms of (1) word identification, (2) reading of speech and (3) pronunciation inhomogeneous condition with $\mathrm{p}$-value $=0,200$ in all three facets of language ability above.

After completion of the intervention and the results are treated with a free sample t-test, the following results are obtained:

1. In the ability of word identification between treatment group and control group, there was a significant difference in the value of $p=0,00$

2. In reading comprehension ability between treatment group and control group, there was a significant difference in the value of $p=0,00$

3. In the pronunciation ability in homogeneous conditions between the treatment group and the control group there was a significant difference with the $p$-value $=0.00$

Thus it appears that the intervention of language skills with a communicative approach using individual learning facilities is greater than the communicative approach using classical learning facilities.

The results of this study support the theory of language learning which says that language skills will develop well if in language learning is accompanied by doing language actions that include listening, speaking, reading, and writing[10]. While the technique of language teaching approach that is currently considered capable of involving the four actions of language is the technique of teaching the language with a communicative approach.

In developing the language skills in children the frequency of exercise also affects the mastery of language skills. The more often the child is given the opportunity to engage in language action the better his mastery of language

\section{CONCLUSION}

The results can be summarized as follows:

1. Prior to following the guidance of language skills with a communicative approach the ability in terms of word identification in the treatment group and control group in homogeny conditions. After the intervention, there was a significant effect of word recognition on the treatment group compared with the control group

2. Prior to following the guidance of language skills with the communicative approach of ability in reading the speech in treatment group and control group in homogeny condition. After the intervention, there was a significant effect of improved speech reading on the treatment group compared to the control group

3. Before following the guidance of language skills with a communicative approach, the ability in terms of the pronunciation of words in the treatment group and control group in homogeny conditions. After the intervention, there was an effect of skill enhancement insignificant word pronunciation in the treatment group over the control group

4. Guidance of language skills with a communicative approach that uses props individually turned out to significantly affect the ability to speak in terms of skills 
word identification, reading utterances and pronunciation of the word deaf children of pre-school age.

\section{REFERENCES}

[1] J. A. Winkelstern and A. E. Jongsma, The special education treatment planner. 2001.

[2] Notosudirdjo;Latifun, mental health theory, and application. Malang: UNM Press, 1999.

[3] J. Hasentab, M; Suzanne; Horner, Comprehensive Intervention with Hearing Impairment Infant and Preschool. London: Aspen System Corporation, 1982.

[4] M. A. Winzer and K. Mazurek, Special education in the 21st century : issues of inclusion and reform. 2000.
[6] E. Jackson, "Health Literacy and the Role of the Speech-Language Pathologist," no. May, 2009.

[7] F. Gaines, R;Helpern, "Language Preference and Communication Development of Hearing Impairment," Am. Anim. Deaf, no. 140, pp. $47-55,1995$.

[8] B. Bakwin, Behavior Disorders in Children. London: B.W. Saunders, 1991.

[9] M. Cruickshank, Psychology of Exceptional Children and Youth. New York: Prentice Hall Inc, 1967.

[10] H. Tarigan, D;Tarigan, Teaching techniques for language skills. Bandung: Angkasa, 1986.

[11] M. Zainudin, Research Methodology. Surabaya: PPS Universitas Airlangga, 1988.

[5] D. Moore, Educating the Deaf Psychology Principles and Practices. Boston: Houghton Mifflin Company, 1991. 